\title{
Co-creating local socioeconomic pathways for achieving the sustainable development goals
}

\author{
Katrina Szetey ${ }^{1}$ (D) Enayat A. Moallemi ${ }^{1,2} \cdot$ Emma Ashton $^{3} \cdot$ Martin Butcher $^{4} \cdot$ Beth Sprunt $^{3,5} \cdot$ Brett A. Bryan $^{1}$
}

Received: 12 October 2020 / Accepted: 1 February 2021 / Published online: 14 March 2021

(c) The Author(s), under exclusive licence to Springer Japan KK part of Springer Nature 2021, corrected publication 2021

\begin{abstract}
The Sustainable Development Goals (SDGs) recognise the importance of action across all scales to achieve a sustainable future. To contribute to overall national- and global-scale SDG achievement, local communities need to focus on a locallyrelevant subset of goals and understand potential future pathways for key drivers which influence local sustainability. We developed a participatory method to co-create local socioeconomic pathways by downscaling the SDGs and driving forces of the shared socioeconomic pathways (SSP) via a local case study in southern Australia through contextual analysis and community engagement. We linked the SSPs and SDGs by identifying driving forces and describing how they affect the achievement of local SDGs. We co-created six local socioeconomic pathways with the local community which track towards futures with different levels of fulfilment of the SDGs and each encompasses a narrative storyline incorporating locallyspecific ideas from the community. We tested and validated the local pathways with the community. This method extends the SSPs in two dimensions-into the broader field of sustainability via the SDGs, and by recontextualizing them at the local scale. The local socioeconomic pathways can contribute to achieving local sustainability goals from the bottom up in alignment with global initiatives.
\end{abstract}

Keywords Sustainable development goals $\cdot$ Shared socioeconomic pathways · Sustainability $\cdot$ Community $\cdot$ Participatory · Scenario

\section{Abbreviations \\ LSP Local socioeconomic pathways \\ SDG Sustainable Development Goals \\ SSP Shared socioeconomic pathways \\ UN United Nations}

Handled by Rajarshi Das Gupta, Institute for Global Environmental Strategies, Japan.

Katrina Szetey

k.szetey@ research.deakin.edu.au

1 Centre for Integrative Ecology, School of Life and Environmental Sciences, Deakin University, Melbourne 3125, Australia

2 Designing Systems for Informed Resilience Engineering, The 4TU Centre for Resilience Engineering, Enschede, The Netherlands

3 Forrest Gateway Project, Forrest 3236, VIC, Australia

4 Fire and Regions, Department of Environment, Land, Water and Planning, Geelong 3220, VIC, Australia

5 Nossal Institute for Global Health, University of Melbourne, Melbourne 3010, Australia

\section{Introduction}

To complement and augment national implementation, the United Nations encourage local authorities and communities to implement the Sustainable Development Goals (SDGs) (UN 2015) at the local scale, facilitated through initiatives such as Localizing The SDGs (UN 2017). This can empower communities and give them an autonomous voice to advance their own local sustainability agenda. However, local communities are heterogeneous in sustainability needs and priorities which requires the global goals and targets to be tailored and localized to align with local priorities (Moallemi et al. 2020b). To guide long-term local planning and decision-making to achieve the SDGs, local communities also need to understand the range of potential future pathways for their region and how they align with local sustainability objectives. Global pathways called the Shared Socioeconomic Pathways (SSPs) have already been developed to support the climate change research community (Ebi et al. 2014; van Vuuren et al. 2014; O'Neill et al. 2017), but these pathways must be tailored to the local or regional scale to be of use beyond a global setting (Absar and Preston 2015; 
Frame et al. 2018). To effectively promote the adoption of local-scale action that is aligned with global-scale sustainability initiatives, researchers and governments must work with local communities to downscale global sustainability goals and co-create pathways to their achievement.

So far, implementation of the SDGs has been primarily a top-down, government-led approach, with targets and actions being set at a global (and increasingly, national) level. Grassroots action for sustainable development-described by Seyfang and Smith (2007, p.585) as "solutions that respond to the local situation and the interests of the communities involved"-is also required to realize the SDGs (Jonas et al. 2014; Moallemi et al. 2019). Localization of the SDGs builds on the principles of Local Agenda 21 , which was a participatory, bottom-up initiative for local authorities to engage with their communities about sustainable development (Coenen 2009). Localization is a process which encompasses the downscaling of the goals to the local level to enable co-creation of pathways in a local context. Localizing the SDGs is intended to be a flexible process; it can mean identifying a subset of SDGs which are relevant to the local scale, or it can refer to a group of SDG targets. There is increasing awareness of the importance of SDG localization (Jones and Comfort 2020; Sterling et al. 2020), and a number of studies have localized the SDGs with a range of methods (ElMassah and Mohieldin 2020; Patole 2018; Tan et al. 2019).

Pathways explore plausible states of the world towards fulfilment of the SDGs (Allen et al. 2019; O'Neill et al. 2019; Zimm, Sperling and Busch 2018). The SSPs are global narratives that describe potential futures based upon challenges to climate change adaptation and mitigation developed by the global change research community (O'Neill et al. 2014, 2017). The SSPs were originally intended to be downscaled by including basic pathways for modelling at global or large regional scales (Riahi et al. 2017; van Vuuren et al. 2017) and extended pathways that build upon the basic pathways at local or sectoral scales. To extend the SSPs, Van Ruijven et al. (2014) suggested adding additional driving forces (the socioeconomic elements around which the SSPs are built) to enhance them, and downscaling so they could apply to different spatial or sectoral scales. Zandersen et al. (2019) extended the SSPs to explore future environmental outcomes for the Baltic Sea and contextualized them to sustainable development outcomes. Other studies have also extended the SSPs to particular regions (Kok et al. 2019; Nilsson et al. 2017; Palazzo et al. 2017). As with the SDGs, global pathways such as the SSPs can also be localized to better represent the diversity of place-specific sustainability contexts.

A number of studies have assessed individual SDGs and targets under the SSPs, for example, poverty (Crespo Cuaresma et al. 2018), child mortality (Lucas et al. 2019), air pollution (Zhang 2015), poverty, and inequality (Byers et al. 2018). Moyer and Hedden (2020) projected limited progress towards several SDGs under the Middle-of-theroad SSP2 and Zimm et al. (2018) suggested broadening the basis of the SSP narratives to encompass all areas of the SDGs. In one of the few national-level assessments, Allen et al. (2019) found that Australia would find it challenging to completely achieve the SDGs under the SSPs without major socioeconomic transformation. However, pathway analysis for the SDGs that relies on the aggregation of data at national or global levels cannot capture the socioeconomic and environmental heterogeneity prevalent at local scales (Patole 2018). While the extension of the SSPs and their assessment against SDGs have been undertaken at the global and national levels, the SSPs and the SDGs have not been explicitly localized and linked (Yang and Cui 2019). Tailoring SDGs and SSPs to the local level can help local communities understand the potential influence of future driving forces in the effectiveness of alternative interventions on sustainability and help achieve the SDGs from the ground up.

Communities, stakeholders, and researchers need to work together to co-create locally relevant sustainability pathways and participatory methods are essential for enabling this collaboration (Halbe, Holtz and Ruutu 2020). These can include superficial activities such as surveys and focus groups, through to more comprehensive methods such as shared visioning (Basco-Carrera et al. 2017; Berland 2019). Participatory methods have been widely used to create pathways and scenarios for sustainability at the local level, and are essential for gaining a local perspective (Bennett, Kadfak and Dearden 2016; Nilsson et al. 2017; Palazzo et al. 2017). They have also been central to planning for the SDGs at national and sectoral levels (Fuldauer et al. 2019; Kanter et al. 2016). To co-create local sustainability goals and pathways, engagement with the local community is essential.

In this study, we developed a participatory approach to localize the global SDGs and SSPs and link them to co-create local socioeconomic pathways. In a case study in southern Australia (see Sect. "Study area"), we used a range of participatory techniques including a Listening Post, Kitchen Table Discussion, Open House, and Visioning Workshop to collect data on the concerns and priorities of local stakeholders about the future sustainability of their community. We used this data along with a contextual analysis of documents to identify priority SDGs and develop locally-relevant socioeconomic pathways towards these goals incorporating ideas provided by the community. Via the development of a new sustainability pathway space, we examined the influence of socioeconomic driving forces on local SDGs and evaluated them through feedback from the community. We discuss the implications of linking the SDGs with the SSPs to co-create socioeconomic pathways which address local challenges yet align with global sustainability goals. 


\section{Materials and methods}

\section{The definition of local socioeconomic pathways}

Local socioeconomic pathways describe potential futures at the local scale based upon different levels of achievement of the SDGs. They are created as a narrative storyline drawn from a suite of assumptions of how local driving forces will affect the achievement of local SDGs under each pathway. Our definition here of driving forces is equivalent to the SSP elements (see O'Neill et al. 2017, Tables 1, 2, 3) which describe major trends such as land-use change or technological advances that will shape the potential ways that the future may unfold (Kriegler et al. 2012; O’Neill et al. 2014; van Vuuren et al. 2012).

We co-created local socioeconomic pathways through two processes: contextual analysis of documents and community engagement (Fig. 1). These processes were fundamental for localizing the SDGs and socioeconomic driving forces which are the basis of our local pathways. The processes provided the opportunity to cross-validate the results and fill data gaps (e.g., using workshop data when documents fall short), and helped reduce biases from different sources (e.g., economic biases in local government plans).

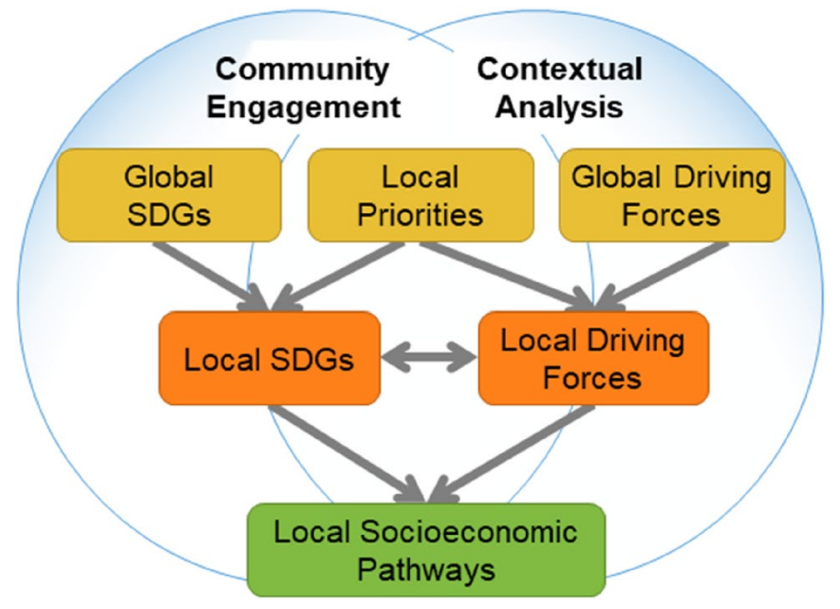

Fig. 1 The process of localizing SDGs and driving forces to create local socioeconomic pathways. The creation of local socioeconomic pathways is underpinned by community engagement and contextual analysis, which are represented by the intersecting circles beneath the boxes. SDGs are localized by identifying which global SDGs interact with local priorities, and driving forces are localized by identifying which global driving forces interact with local priorities. At this stage, the local SDGs and local driving forces are linked by identifying which driving forces influence the SDGs, allowing an additional round of elimination of non-relevant driving forces. The local socioeconomic pathways can then be developed. All of these links and interactions are represented by grey arrows, and these arrows show the process of developing local socioeconomic pathways
Our work was a collaboration between the community and researchers. Knowledge exchange was facilitated via meetings, presentations, and emails, allowing community representatives to participate in developing the narratives by providing community-specific inputs, commenting on draft narratives and validating the relevance of the final narratives.

\section{Study area}

The case study community, Forrest (Fig. 2), lies within a regional area that was once heavily reliant on the forestry industry. It has been a community in transition since the prohibition of logging in 2008 and the concurrent decline of agricultural industries. Since around 2010, tourism and tourism-supporting activities have become dominant in its economy. The local environment is a temperate rainforest, which became part of a National Park in 2005, at risk of wildfire impact and vulnerable to the effects of climate change. Forrest has a highly engaged community who are concerned about their future in the face of climate change and see this as a critical point in their development to switch to a more sustainable path. They have particular concerns regarding bushfire (SDG 13), new wastewater infrastructure (SDG 6), and the diversification of their economy beyond tourism (SDG 8).The population of the community-the township of Forrest plus the local surrounding district-is approximately 450 people. The Eastern Maar are the Traditional Owners of south-western Victoria and custodians of the land.

\section{Collecting data}

\section{Contextual analysis}

The contextual analysis involved a comprehensive review of locally relevant documents undertaken to understand the sustainability context. These included published literature, grey literature, news articles, internet content, and documentation of previous community engagement activities, which were identified through a snowball process with stakeholder guidance. We collected 19 documents relevant to Forrest (SI 1.1). These were systematically examined in Nvivo 12 (QSR International Pty Ltd 2018) and the contents were coded by assigning statements to the 17 SDGs and/or a list of criteria. These criteria were: challenges, historical context, key driving forces, and opportunities. These data informed the definition of local priorities, which assisted with the identification of relevant driving forces and SDGs to shape local socioeconomic pathways (Fig. 1).

We conducted additional research consisting of internet searches for relevant data or reports to gain a more complete understanding of the local context. For example, demographic information principally came from the Australian Bureau of Statistics (Australian Bureau of Statistics 2017), 
Fig. 2 A map of the case study area, in the context of the surrounding region and of Australia

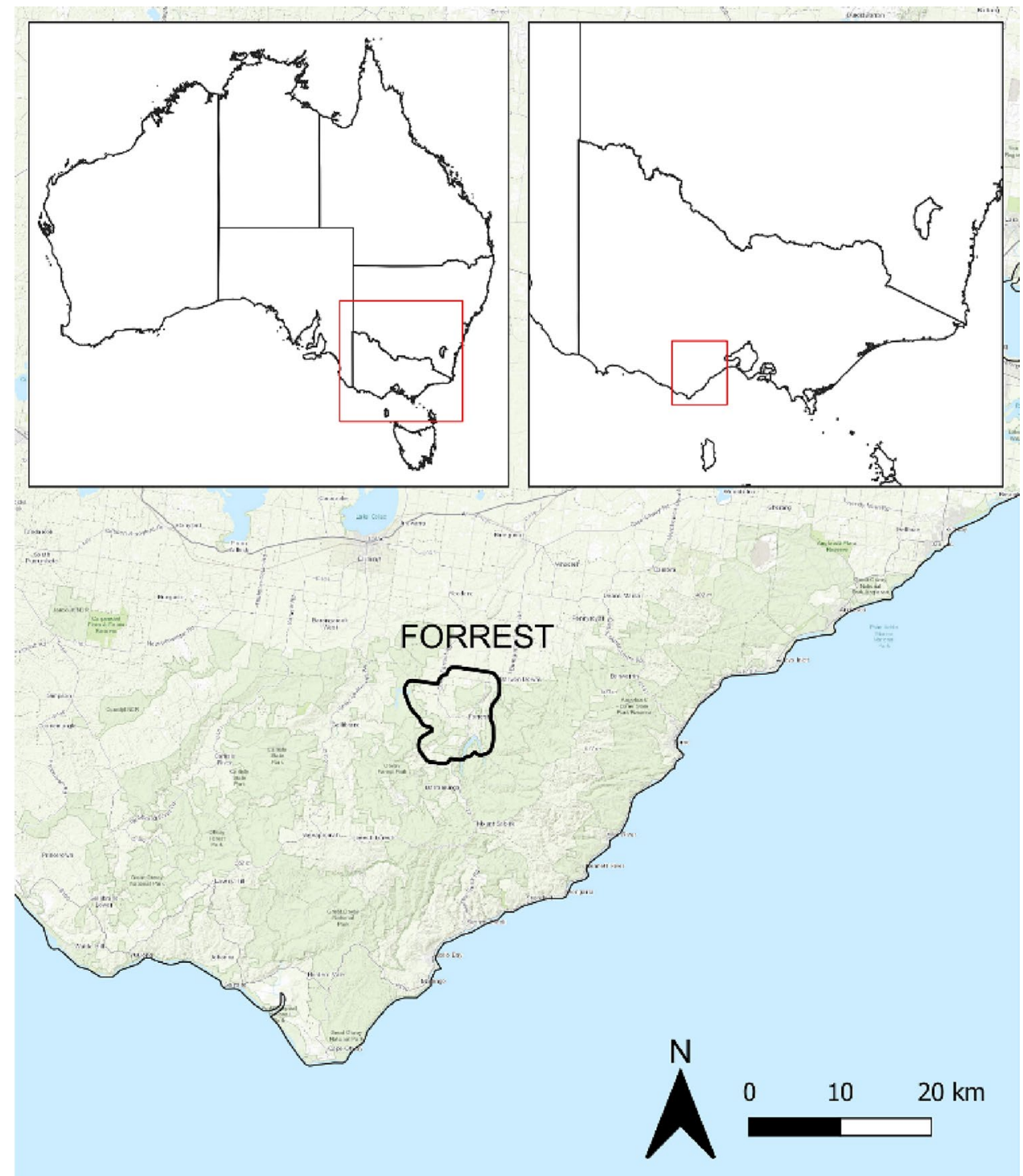

regional growth information was derived from a consultant's report for the local region (SGS Economics and Planning 2018, SI 1.2). We identified the SDGs which were associated with each driving force and described that relationship as per present-day circumstances. For example, the driving force carbon intensity was associated with SDGs 7 (energy), 8 (economy), 9 (infrastructure), 11 (communities), 12 (consumption), 13 (climate) and 15 (land), and the relationship was described as "Forrest is heavily reliant on fossil fuel energy and there is low penetration of renewable energy. This leads to a high share of high carbon intensity in the region, which impairs the achievement of SDGs related to climate action and sustainable consumption" (SI 1.3). The trends, opportunities, and challenges were also described (Table SI 1).

\section{Community engagement}

We conducted a range of participatory activities to ascertain the shared aspirations and normative views of the community for their future. As with the contextual analysis, the community engagement informed local priorities, driving forces, SDGs, and ultimately the local socioeconomic pathway narratives (Fig. 1). To design the community engagement activities (as described below), we followed the principles of community based participatory research, where the community is directly involved with research intended to facilitate change within the community (Holkup et al. 2004; Shalowitz et al. 2009). We aimed to facilitate community ownership of the results with "the local, the present and the demonstrable" (Voinov et al. 2016, p.212). By this we mean that the SDGs are specific to the local community; 
our research seeks to understand the current priorities of the community for their future; and that all knowledge elicited from our research belongs to the community. We characterized the community participation in our work on Basco-Carrera's et al. (2017) modified ladder of participation at the consultation, discussion, and co-design levels, and as both collaborative and participatory on their spectrum of participation. We used four approaches for community engagement:

Listening post Derived initially from Stewart (1994), the essential component of the engagement process (referred to as a 'Speak Out') was to hold a participatory analysis event at a location where people were already present such as a festival or shopping centre. This was redefined as a 'Listening Post' to differentiate the location aspect of the activity compared to holding an 'Open House', which is similar in design and intention but held at a venue where participants have to visit, such as a hall.

For our Listening Post, we set up a table and marquee outside the Forrest township's general store for two mornings when we anticipated there would be significant traffic from local residents. The purpose of this activity was to familiarize the community with the SDGs and receive feedback on issues of concern to the community (SI 1.4). We asked the local residents "we would like to know what you think is important for the future of Forrest." We also conducted a poll for residents to vote for what they considered to be the top three SDGs of relevance for the local community. Each community member who participated was allocated three stickers to vote for their three top issues of concern for Forrest, framed by the SDGs (Figure SI 3c). The weighting of votes was permitted, so participants could allocate more than one vote to an SDG. The total number of participants in the poll was 55 (out of a maximum of 400 community members). Participants could also contribute opinions via free-form text (writing on a publicly visible board) or discussion with researchers, who then wrote the main points on the same board (with permission from the contributor) (Figure SI 3a).

Kitchen table discussion We conducted a facilitated Kitchen Table Discussion (van Hees et al. 2020) with community experts representing different stakeholder groups to discover what they considered important for the future of the community. A community-based collaborator identified eight people of diverse experiences to participate (for example, the group included a farmer, a local tourism business operator, a school administrator, and a government employee; SI 1.5). The facilitator took the participants through a list of questions (Box 1). At the conclusion of the event, the participants jointly decided upon a ranking of the SDGs.
Box 1 The list of questions posed by the facilitator for the Kitchen Table Discussion group

How long have you lived in Forrest?

What do you like about living here in Forrest?

What keeps you here?

What are the community challenges?

There is a lot of talk about the growing rich/poor divide. What does it look like (if at all) in Forrest?

What might be some of the threats to the town?

Semi-structured interviews We conducted semi-structured interviews (Longhurst 2016) with representatives of the local government which administers the township of Forrest (Colac-Otway Shire) to gain an understanding of the community priorities from a local government perspective. We interviewed three representatives who had a close working relationship with, and understanding of the study area; with diverse roles in the organisation including environment coordinator, building inclusive communities officer and tourism development officer. We structured our interview questions framed by the ORID method-Objective, Reflective, Interpretive and Decisional questions (Baptiste 1995) (Box 2).

\section{Box 2 The list of four questions used} in the semi-structured interviews

\footnotetext{
Objective question

a) How long have you been with Colac-Otway Shire?

b) What does your job with Council involve?

Reflective question
}

a) What parts of your job with Colac-Otway Shire involve Forrest?

b) How does your work intersect with Forrest and/or sustainability? Interpretive question

a) What do you see to be the key issues that Forrest is facing?

b) What things do you think we need to consider for the future of Forrest?

Decisional question

a) What do you see to be the key issues for this project?

b) Are there any key actions you think we need to take to achieve our aims?

Open house To extend and confirm our research from the Listening Post and Kitchen Table Discussion, we ran an Open House event (DELWP 2014). At this event, we collected the information gained from the previous 
activities into broad themes and created posters for each theme, illustrated with local images, containing direct quotes from the previous events and posing questions about each theme (Figure SI 5 and SI 6). These posters were hung in the local community hall for two days, and residents were able to visit and provide feedback, either via direct conversation with the researchers, or by writing onto paper adjacent to the posters (SI 1.6). This event was conducted approximately one month after the Listening Post and Kitchen Table Discussion, and there were 23 registered participants. It was held concurrently with another community event to increase traffic and advertised through social media, the local newspaper, and flyers posted throughout the town.

Visioning and ideas workshop To have the community articulate a shared vision for a sustainable future for Forrest in 2030, we conducted a Visioning and Ideas Workshop (Nam 2013). This event was advertised through social media, the local newspaper, and flyers throughout the town, and was conducted approximately one month after the Open House. There were 16 participants in this activity. To elicit this vision, the facilitator took the group through a guided visualization which described a hypothetical walk through the town in 2030, and each attendee wrote down the changes they saw. Then, in small groups, the participants collated these visions into a mock newspaper template and shared them as 'news articles' with the larger group. Following this, the small groups provided ideas for how they would achieve their vision of Forrest, and what tensions they saw with the community aspirations (SI 1.7). After this event, the researchers summarised the information collected through all the community engagement activities into one shared community vision and returned it to the attendees for confirmation and acceptance.

\section{Defining local SDGs}

We localized SDG goals and targets by identifying the community priorities for the future and eliciting their ambitions for a sustainable future (Fig. 1). We generated three SDG shortlists from the contextual analysis and community engagement, and then combined them to obtain a final list of local priority SDGs. Through the contextual analysis, we selected the top six SDGs based on the frequency of related statements across the database of documents. From the Listening Post, we shortlisted the top six SDGs from the community poll. The top six SDGs from the ranking decided upon at the conclusion of the Kitchen Table Discussion formed a third shortlist. We consolidated these three shortlists into one final list of priority SDGs. The SDGs that were common to at least two of the three shortlists were chosen as the local priority SDGs.

\section{Localizing pathways}

We localized the SSPs by co-creating a set of narratives specific to our local community (Fig. 1). The data collected through the activities described in Sect. "Collecting data" was used to localize the socioeconomic driving forces and ideas provided by the community were included in the pathway narratives. We called our narratives the local socioeconomic pathways.

\section{Developing the sustainability pathway space}

In adapting the SSPs to the context of the SDGs, we needed to reframe the conceptual space of possible pathways. The original SSPs are defined in a two-dimensional space based on challenges to climate mitigation and climate adaptation (O'Neill et al. 2014). However, this conceptual space can be adapted depending on the context (Allen et al. (2019). To define our pathways in the context of the SDGs, we constructed a three-dimensional space with each axis representing one of the three dimensions of the SDGs i.e., people, planet, and prosperity (UN 2015). These dimensions are equivalent to the sustainability pillars of society, environment and economy (Purvis, Mao and Robinson 2019), and the SDGs were aligned with these dimensions by Folke et al. (2016) in their 'wedding cake' diagram. We co-created pathways which depicted varying levels of SDG fulfilment along these three axes (Fig. 3). We placed a hypothetical cube on these axes as our sustainability pathway space and identified the corners of the cube which perform well on at least two dimensions as representative pathways (LSPs 1-4). Two additional pathways were defined: one which does not prioritize any dimension as a worst-case (LSP 5) and one in the centre of the cube as Business As Usual (LSP 6-BAU) where there has been little effort to promote sustainability in any dimension.

\section{Identifying local driving forces}

O'Neill et al. (2017) created a list of driving forces for the SSPs, but emphasised that this list was not exhaustive and could be adapted or extended. To link these driving forces with the SDGs, we refined the list of socioeconomic driving forces so that they were appropriate for the local context (O'Neill et al. 2017; Absar and Preston 2015; Frame et al. 2018; van Ruijven et al. 2014). This was informed by knowledge gathered from the contextual analysis and community engagement, as we had identified the key community concerns and vision for the future. Refining entails both elimination of driving forces and addition of new ones, 


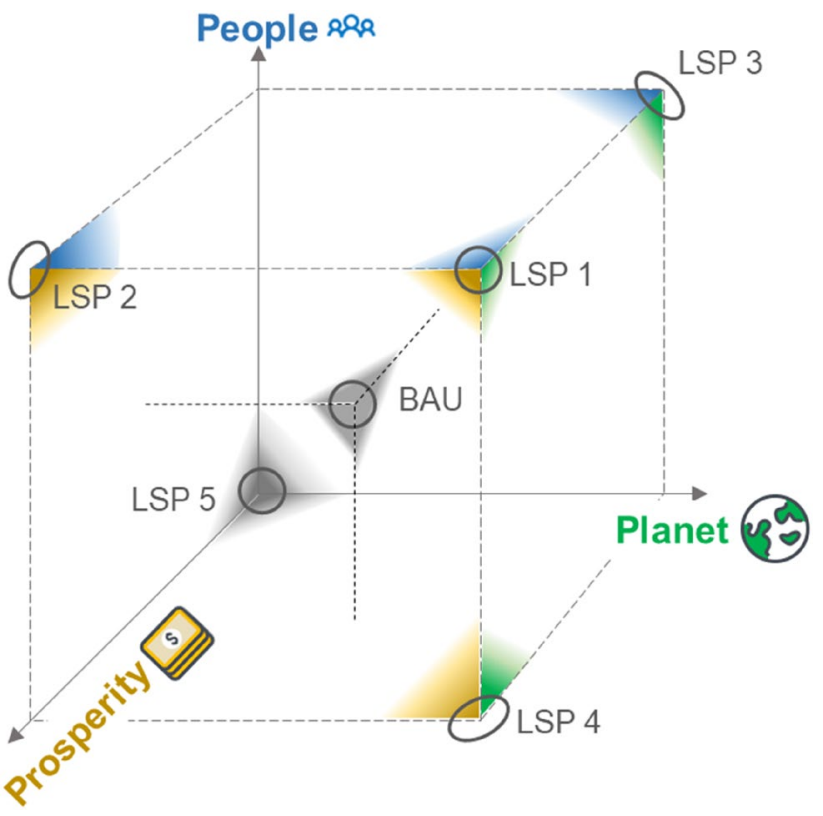

Fig. 3 Axes representing the conceptual space in which the pathways sit. Each axis represents one of the dimensions of the Sustainable Development Goals (people, planet, and prosperity). One pathway sits at each outer vertex of a hypothetical cube on these axes, and there is a pathway at the approximate centre point of the cube representing Business As Usual (BAU). The vertices are color-coded to represent the dimensions which are prioritized for that pathway: yellow-prosperity; green-planet; and blue-people. LSP 5 and BAU are not color-coded as no dimensions are prioritized in these scenarios

based on relevance to the local context. We excluded those driving forces which are global in nature (e.g., Globalisation or International cooperation) as our local community has a low population and its economy is mainly driven by the local region; and those which do not impact the fulfilment of the priority SDGs at the local scale. We added new driving forces (e.g., tourism) which were identified as locally important (Table SI 1). To link the socioeconomic pathways and the SDGs, we identified the driving forces which influenced the SDGs and described the impact that influence would have on the fulfilment of the SDGs. If a driving force had one-third or fewer locally prioritized SDGs associated with it, then it was eliminated-in this case, 0,1 or 2 SDGs. The remainder were deemed to be influential local driving forces and therefore key in shaping the LSPs.

\section{Evaluating the effect of local driving forces on local SDGs}

Using the collected data, we assessed how the driving forces influenced the local SDGs under each local pathway in Fig. 3. This resulted in six detailed assumptions tables, one for each pathway. An example assumption for the impact of driving force carbon intensity (i.e., level of fossil fuel use) on SDG 15 (Life on Land) under the people and prosperity pathway is:

"Use of fossil fuels is high, which has a negative effect on the environment due to increasing greenhouse gas emissions, which strengthens climate change".

We generated each assumption through extrapolation of the emerging trends, challenges, and opportunities identified in the contextual analysis (see SI 1.3). In the previous example, we relied on challenges for generating the assumption as the pathway did not prioritize planet, and SDG 15 is an environment (planet) SDG. However, for the same driving force of carbon intensity and the same SDG 15 but under the planet and prosperity pathway, we extrapolated upon the opportunities (SI 1.3) and generated the assumption:

"There is protection of terrestrial ecosystems, and cessation of logging. This lessens the effect of carbon intensity".

These detailed assumptions were assembled in six tables (SI 2). We synthesized these detailed assumptions and described them visually, with color representing a positive, negative or neutral impact of the driving forces on each SDG, and arrows indicating the change in the impact of the local driving forces with respect to each SDG over time.

\section{Developing narratives for local socioeconomic pathways}

We consolidated the assumptions of how each driving force influenced different local SDGs, under each pathway. For example, the consolidated assumption for Carbon intensity, under LSP 1, is:

"International tourism has a negative impact on carbon intensity (through air travel), but locally there are positive impacts and policies, such as a renewable energy microgrid, halting deforestation and protection of terrestrial ecosystems."

From these assumptions, we developed six pathway narratives which depicted the potential futures of the local community under the pathway conditions.

\section{Testing and validation of pathway narratives}

To validate and confirm the pathways with the local community, the detailed assumptions were returned to three community representatives for review. These representatives examined the researcher synthesis and provided new ideas to be incorporated into the assumptions and the narratives. The results were then presented in two seminars for the local community to disseminate the outcomes. 


\section{Results}

\section{Defining local SDGs}

We identified three sets of priority SDGs, independently from each other, from three sources: the contextual analysis and two community engagement activities (Listening Post and Kitchen Table Discussion) (Fig. 4). We shortlisted the SDGs which were identified as important in two or more sources, leading to a set of six common SDGs, which were Good Health and Wellbeing; Clean Water and Sanitation; Decent Work and Economic Growth; Sustainable Cities and Communities; Climate Action; and Life on Land (Fig. 4). There was significant overlap in the three sets, and thus only three SDGs were eliminated from the total pool of nine.

\section{Localizing pathways}

We found from the contextual analysis that tourism was a major driving force in the local economy; there was a strong concern in the community around bushfire impact and other climate-driven threats; and there was a desire to recognize and incorporate local Indigenous culture. From the original list of 30 SSP driving forces, we added three that were identified as important issues (Tourism, Resilience against climate change impacts, and Indigenous rights/traditional knowledge), and eliminated six due to a lack of relevance to the local scale (Urbanisation, Globalisation, International cooperation, Environmental policy, Policy orientation, and Institutions) (SI 1.3). By identifying relationships between the driving forces and the SDGs, we linked them and then filtered out those which had two or fewer local SDGs associated with them, leaving a final list of 21 local driving forces (Table 1).

\footnotetext{
Left of pair $=$ References $(\%)$

Right of pair $=$ Votes $(\%)$

Solid fill = Priority SDGs

I/: Shaded fill = Non-priority SDGs

- Kitchen Table Discussion

- Final priority shortlist
}

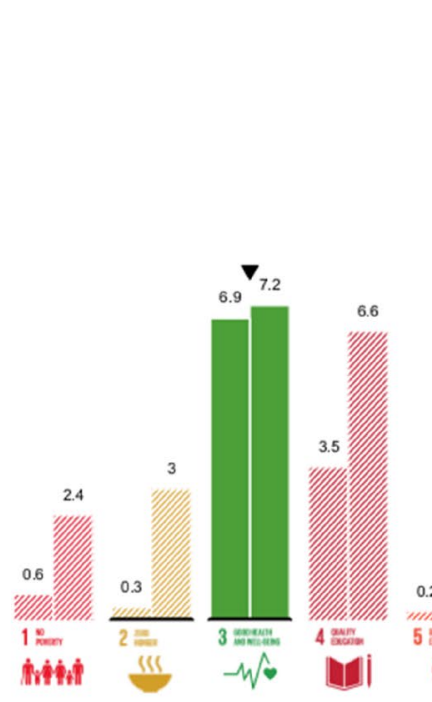

Fig. 4 Results of SDG selection from the contextual analysis and community engagement. Bars on the left of each pair are the contextual analysis results, and bars, on the right of each pair are the Listening Post poll results. The columns with a solid colour fill indicate the priority SDGs identified in the contextual analysis and Listening Post

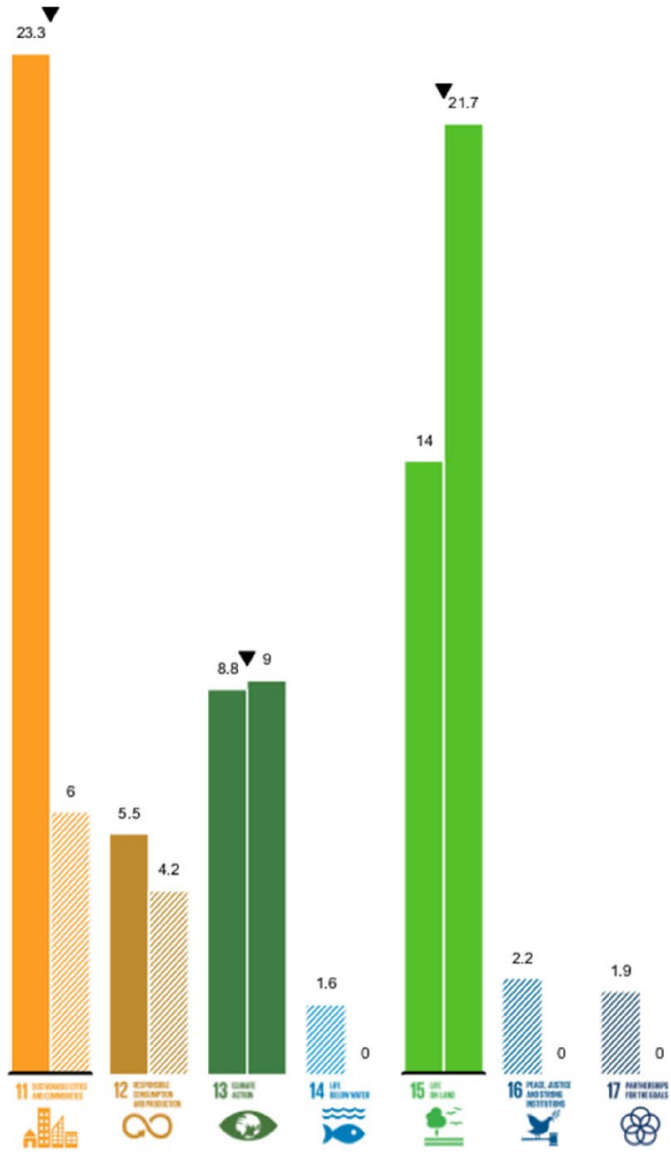

poll, with the percentage at the top of the bar. The SDGs selected at the end of the Kitchen Table Discussion are identified with a black line at the bottom of the pair of bars, and SDGs that are common to two or more activities are identified with a black triangle at the top of the bars 
Table 1 The influence of socioeconomic driving forces on the SDGs. Greyed-out columns indicate non-local SDGs. Colored columns indicate the localized priority SDGs (3, 6, 8, 11, 13 and 15). Greyed-out rows indicate driving forces which have a relationship with two or fewer local SDGs, and therefore are considered non-relevant for the local context. Solid (colored or grey) circles indicate a link between the SDG and the driving force. Empty (colored or grey) circles indicate no link between the SDG and the driving force

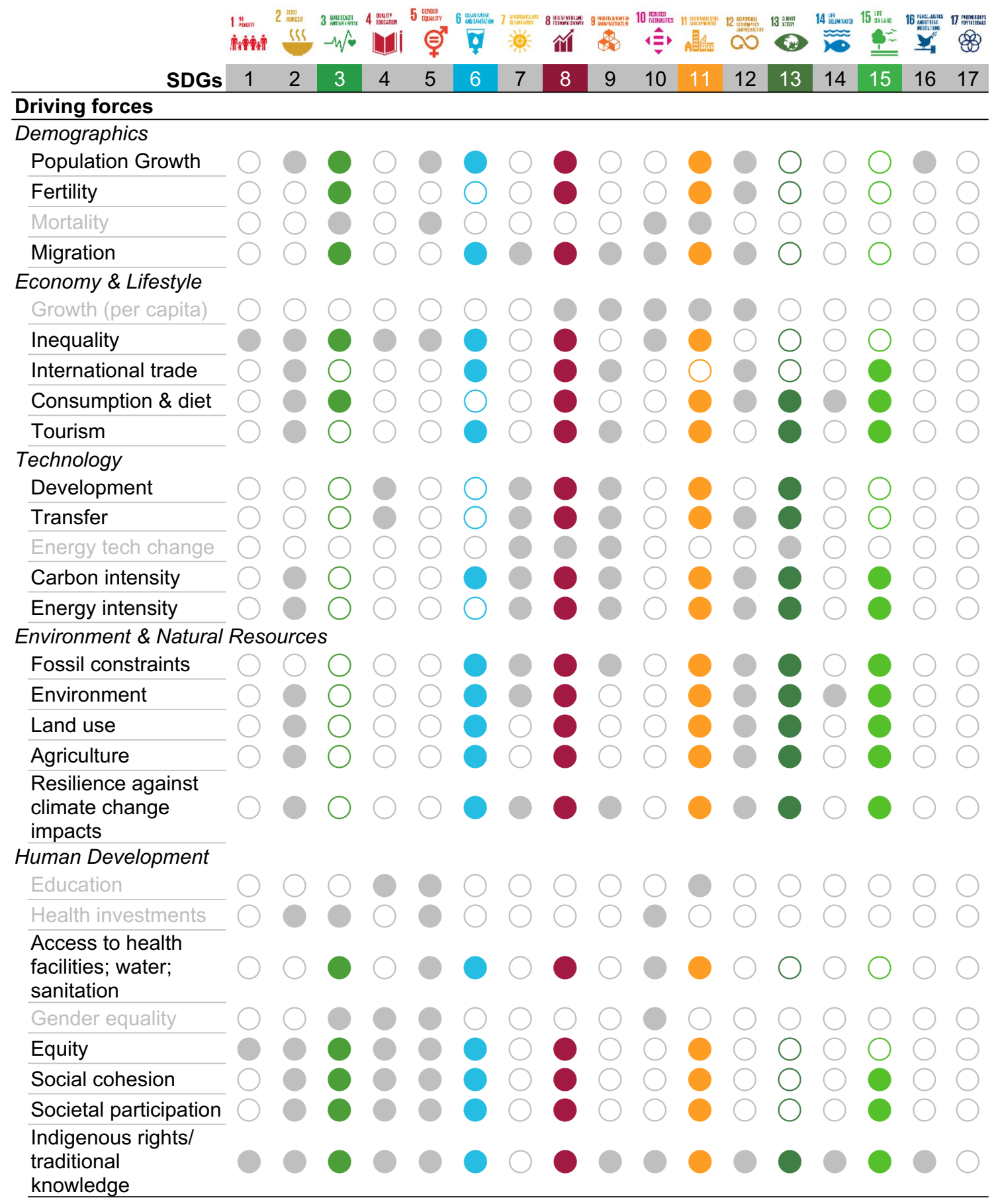

We described how each driving force influences the local SDGs under each pathway, resulting in 756 individual qualitative assumptions (SI 2, an example of these are contained in Fig. 5). We visualized the effects of the local driving forces as described in the assumptions, where the impact of each driving force is specific to the context of the pathway, and also specific to the context of the SDG (Fig. 6). For example, the driving force population growth has the following assumptions under SDG 6 (clean water and sanitation) for LSP 1: 


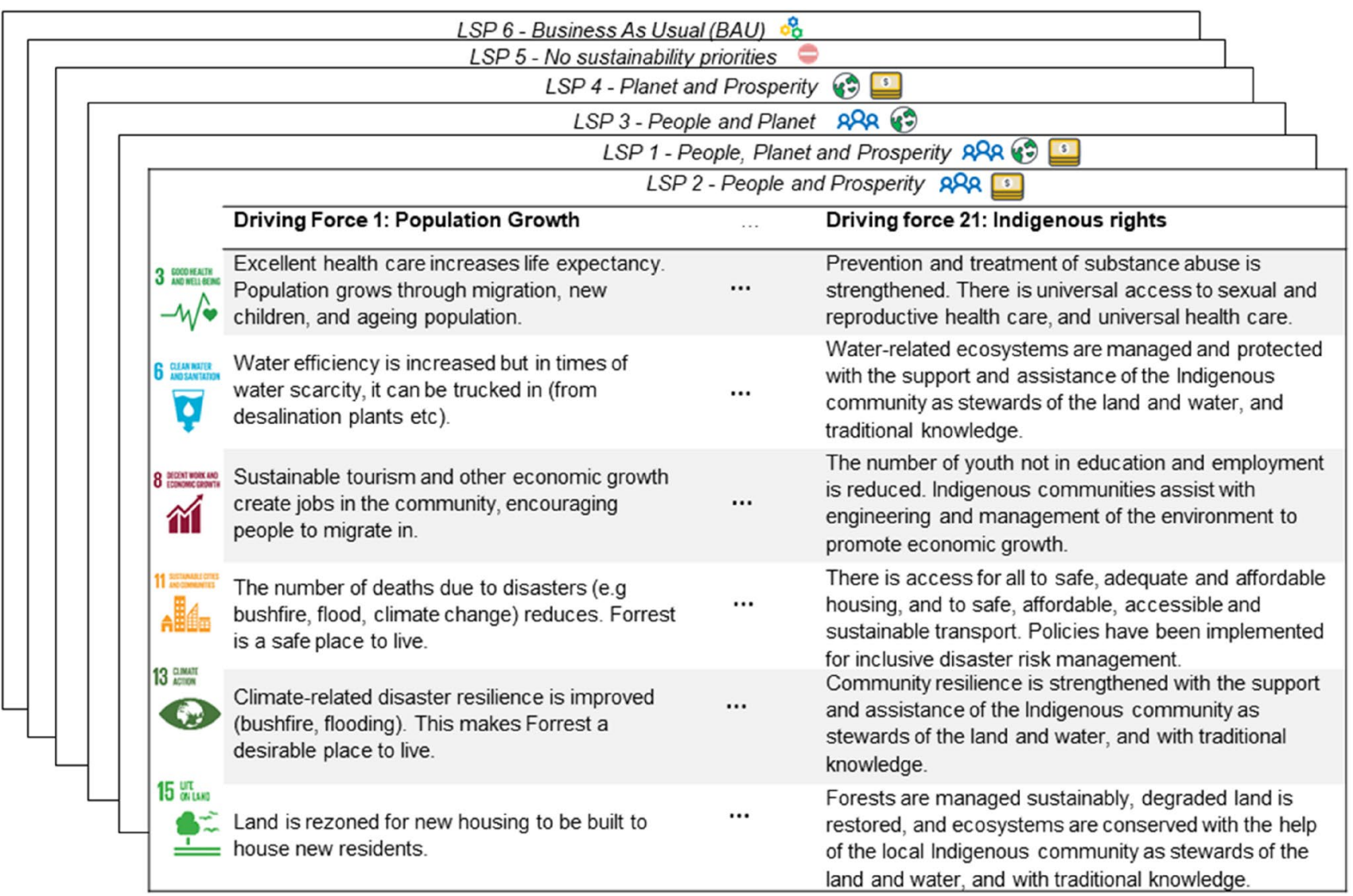

Fig. 5 An example of the detailed assumptions as contained in SI 2. For each pathway, there is an assumption of how each driving force influences each of the six local SDGs. In total, for all six pathways, there are 756 individual assumptions

"Water is used efficiently and sustainably, within the carrying capacity of the community."

Here we have all dimensions prioritized, so water use is sustainable and results in a positive outcome for SDG 6, and "within the carrying capacity" indicates no net change over time, hence the arrow for this assumption is static and colored green. By contrast, the same driving force and SDG under LSP 2:

"Water efficiency is increased but in times of water scarcity, it can be trucked in (e.g. from desalination plants)."

This LSP prioritizes only people and prosperity, which means that environmental outcomes are disregarded. Desalination of water is an energy-intensive process, and without clean energy, this is a negative environmental impact (as detailed under the energy intensity driving force). However, the overall outcome for LSP2 is general population growth, with a neutral impact on SDG 6, represented with a yellow arrow indicating moderate growth.

The best outcome for the local SDGs occurs with LSPs 1 (people, planet, and prosperity) and 3 (people and planet), while LSP 2 (people and prosperity) shows poor environmental outcomes, LSP 4 (planet and prosperity) has both poor social and economic outcomes, and LSP 5 (no dimensions prioritized) has poor outcomes for all SDGs. LSP 6 (BAU) has neither excellent nor exceptionally poor outcomes, however, the impact of the driving forces indicates that the SDGs are unlikely to be achieved without major changes.

We consolidated the detailed SDG impact assumptions into one single outcome for each driving force, for each scenario (Table SI 8). From these, we developed six pathway narratives (Box 3). 


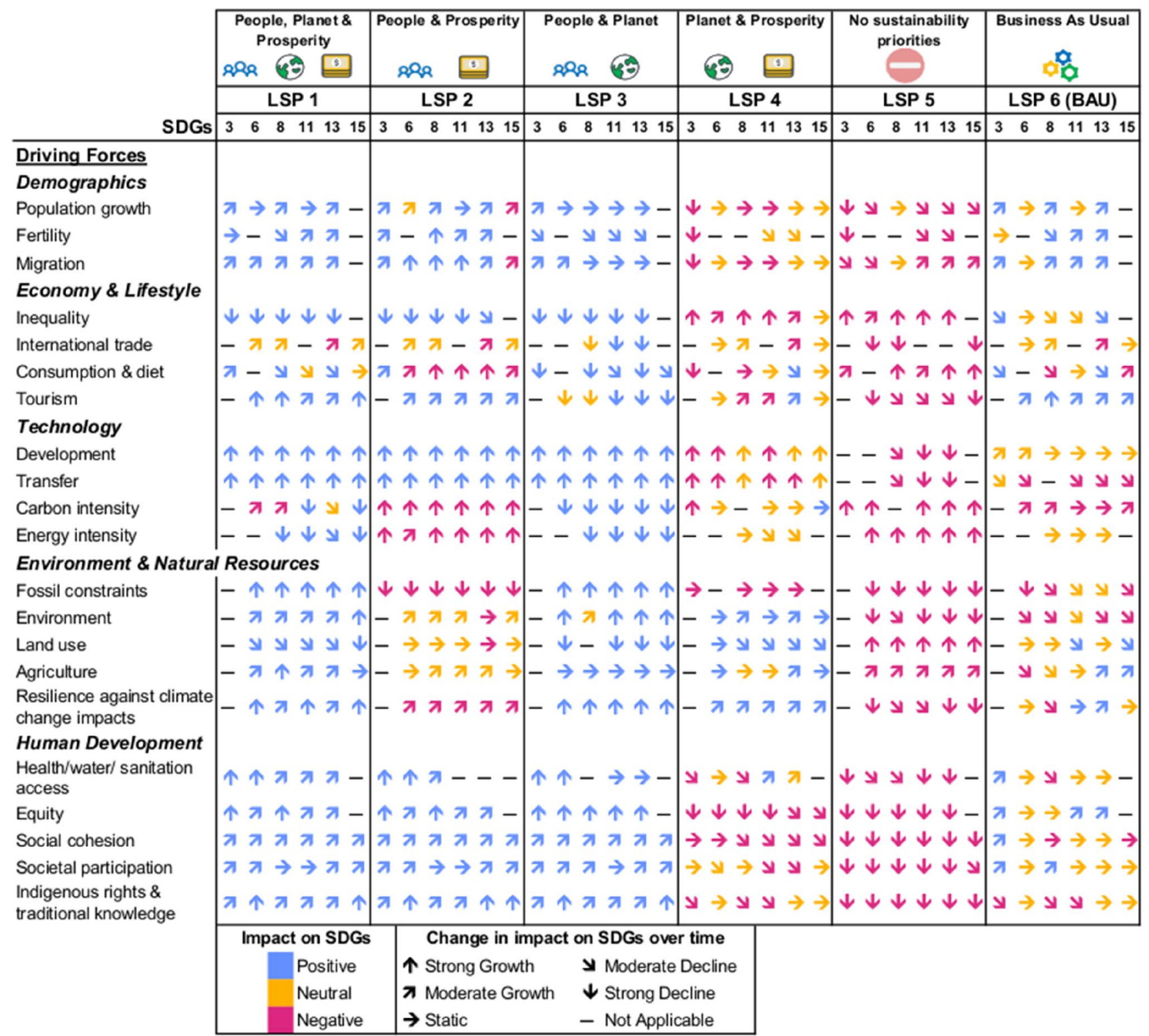

Fig. 6 Visualization of the impact of the local driving forces under each pathway, based upon the detailed SDG impact assumptions (SI 2 ). The color represents the impact on the SDG with respect to that driving force under the conditions of each pathway, and the direction of arrows represents the change in impact on the SDGs over time 


\section{Box 3 The local socioeconomic pathway narratives}

\section{Local Socioeconomic Pathway narratives} LSP 1: People, Planet and Prosperity
The town shifts gradually to a more sustainable path. There has been significant take-up of
renewable energy, particularly solar panels, and the town generates all its own energy through a local microgrid (SDG 7). The condition of the environment is improving over time thanks to changes in policy and management - for instance, there are strong regulations on land use to avoid environmental trade-offs (SDG 15). Domestic tourism is moderate and well managed to keep the environment pristine, focused on green- and eco-tourism, and niche agriculture such
as mushrooms, plus examples of regenerative farming also encourage visitors (SDG 8). The as mushrooms, plus examples of regenerative farming also encourage visitors (SDG 8). The
region becomes known for small-scale sustainable farming, and Community Supported Agriculture models (where consumers pay in advance for regular deliveries of produce) are implemented to share the costs and risks of farming with the community (SDG 2). Niche agriculture and international tourism promote a moderate level of international trade at the loca scale, although international tourism has trade-offs against carbon intensity, primarily through air travel (SDG 13). The town is susceptible to bushfire and drought but managed burning and sustainable water use mitigate the threat (SDG 6,13,15). Additionally, drought-resilient water infrastructure and a sewerage system are built which increases resilience to climate chang impacts (SDG 6,13). Forrest becomes an incubator for climate change resilience and technology research and this encourages the growth of the local economy beyond tourism (SDG 13). At a social level, medical services and excellent health care are available within the township (SDG 3). The population grows slowly through in-migration and an ageing population, and alternative housing options such as co-housing emerge to sustainably house new residen and increase the sense of community (SDG 11). Forrest is a desirable, safe reduced/eliminated and equity is high (SDG 1, 10). The community values the Indigenous heritage of the land, recognises traditional owners and adopts traditional land management practices (SDG 10,15). The community is small, socially engaged, and close-knit, and so have an advantage in being able to pull together to achieve implementation of the SDGs (SDG 17).

LSP 2: People and Prosperity

On this pathway, there has been an economic boom, allowing investment in socia institutions and the 'lifting up' of many disadvantaged peoples (SDG 1, 10). This has occurred in concert with the exploitation of fossil fuel reserves and intensive management of the environment, resulting in an increased pace of climate change (SDG 13,15). Australia has high fossil fuel reserves and has had minimal take-up of renewable energy, impairing achievement of climate action and sustainable consumption SDGs (SDG 7, 11, 13). In Forrest, results of environmental management include earthmoving to create firebreaks for bushfire prevention and fracking for fossil fuels (SDG 13,15). These management techniques, combined with climate change, have a negative effect on biodiversity even though improvements are seen in other ways (such as increased bushfire resilience) (SDG 13,15). Land use regulation leads to slow decline in the rate of native deforestation, replaced with timber plantations (SDG 15). A tourists and new residents, while desalinated water is trucked in when required (SDG 6, 8). Agriculture such as dairy and beef farming, and mushroom growing is highly managed and resource intensive; there is a rapid increase in productivity. The region becomes known for small-scale sustainable farming (SDG 2). This, as well as mountain biking, encourages domestic and international tourism to the region. International tourism has trade-offs against carbon intensity, principally from air travel emissions (SDG 8,13 ). There are high levels of consumption, materialism, and meat-rich diets (SDG 12). There is rapid technology development and Forrest becomes a development hub for new tech, allowing full and productive employment and growth in the local economy (SDG 8). The community values the indigenous heritage of the land and recognises traditional owners and traditional management indigenous heritage of the land and recognises traditional owners and traditional managem
practices for the local environment (SDG 10,15). Poverty and inequality are significantly practices for the local environment (SDG 10, 15). Poverty and inequality are significantly
reduced for all members of the community, so Forrest is a safe and desirable place to live, and the population of the town grows through migration, births, and an ageing population (SDG 1,2,
the the population of the town grows through migration, births, and an ageing population (SDG
10). Medical services are available within the town, and excellent health care improves 10). Medical services are available within the town, and excellent health care improves
outcomes post-natally and for elderly people (SDG 3). New housing is built in rezoned land to outcomes post-natally and for elderly people (SDG 3). New housing is built in rezoned land
house new residents (SDG 11). Social cohesion and engagement is high, meaning the community is able to pull together to achieve implementation of the SDGs (SDG 17). The acceleration of climate change due to forces outside of the local level of control limits the successful outcomes from SDG implementation (SDG 13).

\section{RQR}

The capitalist mantra of growth at all costs has been abandoned in this pathway (SDG 8). Ther is no drive to grow the town beyond its current capacity. Forrest has excellent health care (SDG 3), a new sewerage system (SDG 6), protection of local ecosystems (SDG 15) and enough jobs, funded by reinvestment of profits into the community (SDG 8). Alternative housing options such as co-housing emerge to house new residents, and policies to limit the use of housing for profit (for rental and tourism) increases available

housing supply (SDG 11). Water scarcity is substantially reduced due to water reuse from the new sewerage system and improvements to water collection methods (SDG 6) and the community is resilient to disasters (SDG 13). Forrest is therefore a desirable place to live and raise families, although the fertility rate is below replacement and there is social pressure to limit children to one per couple (SDG 12). Economically, all forms of tourism decline as it has too high an impact on climate change (SDG 8), but in its place, Forrest becomes a development hub for climate change adaptation and resilience research, resulting in fulfilling employment and assisting with ecosystem management and disaster resilience (SDG 8,13). There are renewable energy microgrids in the greater Otway region and electric vehicle chargers available in the town (SDG 7). There is clean and accessible public transport available to travel to local centres such as Colac and Geelong, but travelling long distances is more difficult, and the community becomes a little isolated (SDG 10,11). The indigenous community assist in protection, restoration and management as stewards of the land and water, and all indigenous
rights are recognised and have been enshrined in the constitution (SDG 6,10 15). Ecosystem protection and a halt to deforestation sees improvements in $\mathrm{CO}_{2}$ capture (SDG 13, 15). Sustainable agricultural practices and communal agricultural models allow the whole community to share the labour and output of farming (SDG 2). Seed sharing becomes widespread (SDG 2).
The community are highly cohesive and engaged, and are focused on achieving the SDGs that do not emphasize economic growth for growth's sake (SDG 17).

\section{(3)}

LSP 4: Planet and Prosperity The gap between the haves and have-nots has widened (SDG 10). Poverty and inequality are high and disadvantaged people are crowded out of the town due to rising housing costs (SDG 1
10,11 ). Access to health care is expensive and limited (SDG 3), while privileged people moving to Forrest limit the number of children they have as they see this as having a positive impact on sustainability (SDG 12). The local environment is a drawcard for migration into the town and tourism, and thus new and existing residents make efforts to preserve the environment for economic and their own benefits (SDG 6, 8, 15). Sustainable agriculture lessens the impact of agriculture on the environment and on climate (SDG 2). Consumption, like many things, is stratified: rich people have better access to sustainable resources while disadvantaged people are more likely to opt for cheaper, resource intensive products (SDG 12). There are plans for a new sewerage system, but there is division over the cost (SDG 6). Renewable energy and electric vehicles are available to those who can afford it, although the cost is prohibitive for many and resource efficiency is uneven across the community (SDG 7, 12). Forrest becomes a development hub for new technologies, including for climate adaptation and resilience - this encourages the growth of the local economy but prices people out of the housing market as prices rise due to demand (SDG 8,11,13). Community cohesion and participation is low and stratified: only privileged community members believe that SDG implementation is in the best interests of the community (SDG 17). There is a low chance of successful implementation of the SDGs as an integrated and holistic set of goals in Forrest.

\section{LSP 5: No sustainability priorities}

This pathway is characterized by an insular perspective. Government policies change to focus on energy (SDG 7) and agricultural security (SDG 2) at the expense of education (SDG 4), health (SDG 3) and the environment (SDG 6,13,15). Inequality is high and the community has regressed back to the days of high economic disadvantage (SDG 1, 10). Consumption is materials intensive and meat consumption is high and unsustainable, and only available to those who can afford it (SDG 12). Low investment and the abandonment of policy and management results in serious degradation of the environment (SDG 6,15). Likewise, with minimal regulation for land use, deforestation continues, logging and large-scale agriculture intensifies (SDG 15) and sustainable agriculture practices decline (SDG 2). The effects of climate change have narrowed the window to carry out prescribed burning and increased the community's susceptibility
to bushfire (SDG 13,15$)$. Water use and resources are not managed sustainably and there is no guard against drought (SDG 6). There has been minimal take-up of renewable energy such as solar panels, so unconventional fossil fuel resources (e.g. fracking) are exploited in order to provide energy security (SDG 7). The internet is not reliable, deterring people from starting local businesses, so the economy is neither diverse nor flourishing (SDG 8). There is some domestic 13). Health services are not available close by, only in the major centres (Geelong, Melbourne) 13). Health services are not available close by, only in the major centres (Geelong, Melbourne),
and they are difficult to access (SDG 3). This has an impact on post-natal health outcomes (SDG and they are difficult to access (SDG 3). This has an impact on post-natal health outcomes (SDG
5 ). Indigenous rights and recognition are no longer considered at all (SDG 10). Land is rezoned 5). Indigenous rights and recognition are no longer considered at all (SDG 10). Land is rezoned
for new housing to house new residents (SDG 11), but Council are unwilling to consider sewerage for the township so any new housing developments must have septic systems (SDG 6). The community is small and close-knit; few community members are convinced that SDG mplementation is in the best interests of the community, so there is a low chance of successful SDG implementation (SDG 17)

LSP 6: Business As Usual (BAU)

This is a path in which not much changes from the status quo. The population grows slowly, through migration, births and an ageing population. Health care is excellent, although access to health services is somewhat limited within the town (SDG 3). Forrest is a safe place to live, and an attractive prospect for families with young children and 'treechanging' retirees (SDG 11). However, the escalation of house prices and lack of available rental properties are crowding once coming of age, leaving a demographic gap in the $18-30$ year old range (SDG 11, 12). There are pockets of disadvantage but the community support each other when they are in need (SDG 1, 10). Indigenous rights are paid lip service and little changes for indigenous recognition (SDG 10). Domestic tourism is moderate, focused on large-scale events and mountain biking, and investment in mountain bike trails and public amenities lowers the impact on the environment (SDG 8, 15).International tourism has trade-offs against carbon intensity (from air travel, SDG 13), but locally there are positive signs, such as investigation of a renewable energy microgrid (SDG 7). To diversify the economy, there has been an attempt to promote Forrest as a technology intensive, and diets contain unsustainable levels of meat (SDG 12). The environment continues to intensive, and diets contain unsustainable levels of meat (SDG 12). The environment continues
experience degradation, however regulations on land use lead to a slow decline in the rate of experience degradation, however regulations on land use lead to a slow decline in the rate
deforestation, which eventually ceases (SDG $6,13,15$ ). Small-scale agriculture is locally deforestation, which eventually ceases (SDG 6, 13, 15). Small-scale agriculture is locally
sustainable (SDG 2), and while there is an increase in large-scale agricultural productivity, there is not a concurrent increase in employment (SDG 8). Managed burns reduce bushfire risk (SDG 13, not a concurrent increase in employment (SDG 8). Managed burns reduce bushfire risk (SDG 13,
15 ), and restrictions on water use protects against drought (SDG 6, 13), however water supplies $15)$, and restrictions on water use protects against drought (SDG 6, 13), however water supplies
are vulnerable to sustained drought (SDG 6). The Forrest community take the initiative on climate resilience projects as they receive little support from Council or government (SDG 13). The town resilience projects as they receive little support from Council or government (SDG 13). The town
is unsewered; Barwon Water are investigating reticulated sewerage but it will come at a cost is unsewered; Barwon Water are investigating reticulated sewerage but it will come at a cost (SDG 6). The community is small and close-knit, but not all community members are convince successful holistic SDG implementation (SDG 17). 


\section{Testing and validation of pathway narratives}

Climate change (particularly the effect on bushfire vulnerability), diversity in the local economy, and a shortage of housing were identified as major aspects of local sustainability by stakeholders which were already represented in our narratives. Expert feedback also highlighted an overemphasis on international tourism, the need to distinguish between local responses and higher-level factors, and criticized our original response to the social cohesion and societal participation driving forces for approaching SDG achievement as a monolithic concept. We revisited the narratives and modified them so as to better distinguish domestic and international tourism while de-emphasizing the latter, and reworded the sections referring to SDG achievement to indicate that particular pathways are more likely to focus on achieving subsets of the goals. Rather than distinguishing the local and higher-level factors within the narratives (as higherlevel factors still impact the local scale even if, for example, national policy on climate change cannot be changed at the local scale), we included mention of this dichotomy in the discussion. All feedback received on the pathway narratives is listed in the Supplementary Information (S4).

\section{Discussion}

In this paper, we used participatory processes to localize and link the shared socioeconomic pathway driving forces to the SDGs and co-created local socioeconomic pathways that depict futures with different levels of SDG fulfilment. We developed a new sustainability pathway space based upon the three dimensions of the SDGs (people, planet, and prosperity) to accommodate these local socioeconomic pathways, which were as divergent from each other as possible within that space (Fig. 3). In the local socioeconomic pathways, we have included a combination of broader factors (such as international trade) that are not influenced by decisions made within the community, as well as locallydetermined variables (such as a microgrid). LSP 1 frames a future where all sustainability dimensions are prioritized; LSPs 2, 3 and 4 each prioritize only two dimensions at the expense of the third; LSP 5 has no sustainability priorities; and LSP 6 (BAU) projects a future where current trends continue unchanged. We validated these pathways with review by local community representatives and revised them based upon their feedback.

\section{The need for local socioeconomic pathways}

While there have been studies which extend the SSPs to be regionally relevant (Absar and Preston 2015; Frame et al. 2018; Kok et al. 2019; Nilsson et al. 2017; Palazzo et al.
2017; Reimann, Merkens and Vafeidis 2018; Zandersen et al. 2019), and additionally studies which incorporate SSPs and SDGs at a sub-global scale (Allen et al. 2019; Gil et al. 2019; Moyer and Hedden 2020), a new approach was needed to address the unique challenges of assessing the achievement of the SDGs (Allen, Metternicht and Wiedmann 2016, 2017), at both global and local scales. By downscaling and linking the SDGs to the existing pathway framework of the SSPs, we have provided a consistent and tested method to generate pathways that can be used with any SDG implementation. Our work focused specifically on the localization of these global frameworks, but we anticipate that this concept of sustainability pathways created using the sustainability pathway space would work at any scale.

Several studies have argued that the SDGs are not internally consistent, that is, the achievement of some targets will impede the achievement of other targets (although, the converse is also true, where achieving some targets will enable the achievement of others) (Kroll, Warchold and Pradhan 2019). This necessitates the realization of trade-offs in implementation outcomes (Breuer, Janetschek and Malerba 2019; Hinz et al. 2020). This can be seen from our work in the synthesis table (Fig. 6), where LSP 1 (a utopia where the SDGs have been achieved) still features negative outcomes for carbon intensity, as a direct result of air travel fuelled by international trade. Mapping the SDGs to sustainability pathways permits modelling and qualitative descriptions so that these potential trade-offs can be quantified and made clear.

Here, the mapping of SDG outcomes to pathways informs the interactions between the key determinants of each SDG in the future, and thus provides the backbone for the model structure. The model will then allow researchers to reproduce and quantify the impacts of many scenario drivers, and their interactions with one another and with the SDGs, as well as identifying internal feedback mechanisms. Such modelling has been undertaken at global scale (e.g., FeliX: Walsh et al. 2017; Moallemi et al. 2020a), but we intend to perform similar modelling at the local scale.

\section{How the local socioeconomic pathways can influence policy}

The local socioeconomic pathways we have co-created here will be tested via modelling in future research, however in their current narrative form, they still have the capacity to influence local policy. In future research, we will undertake the co-writing of a community plan based upon the SDGs, and the local sustainability pathway narratives will be included in the published version as a demonstration of possible futures for the community if their aspirations have (or have not) been achieved. This community plan will be used to guide investments and decisions made by local 
government and agencies, thus having a direct impact upon the future of the community.

This work was finalized during the COVID-19 pandemic, and the pathways as developed here did not take into account the effect of travel restrictions on tourism, which is a central feature of Forrest's economy. Gössling et al. (2020) found that there is an opportunity to reform global tourism to be more aligned with the SDGs as a result of global disruption to the sector, and that this could entail a focus on domestic, less carbon-intensive tourism. The global disruption from COVID-19 also opens the broader question of whether the achievement timeline for the SDGs should be extended beyond 2030. The UN (2020) has acknowledged that COVID-19 will affect progress on the SDGs but has not suggested an extension. The local socioeconomic pathways could be used more generally in communities to develop pathways as they emerge from COVID-19, and to explore implications for achieving the SDGs in a post-pandemic world.

\section{Comparison to the global shared socioeconomic pathways}

The local socioeconomic pathways examine storylines for local futures, in contrast to the global SSPs which describe global futures. However, the goal was not to create equivalent pathways to the global SSPs, as was the case with Kok et al. (2019), but to create pathways that had a different spatial scale and a different conceptual basis. Rather than considering challenges to climate adaptation and mitigation, our goal was to describe scenarios that portray different levels of fulfillment of the SDGs. This was the motivation behind the development of the sustainability pathway space (Fig. 3). But by using the shared socioeconomic pathway driving forces to structure the local pathways, we have based our pathways on a framework which has been in development for 10 years and is well tested. This ensures consistency of the scenarios and allows comparisons to be made both within the set of local pathways and with other sets of SSPs.

The pathways developed here have a broader span than the global SSPs, although there is some alignment between the global pathways and these local socioeconomic pathways. Of particular interest are the divergent pathways, which are LSPs 3 (people and planet) and 4 (prosperity and planet). LSP 4 has a strong relationship with global SSP4, although LSP 4 has a heavier focus on prosperity and the implications of that change the outcome of the nature of inequality found at the local scale. More particularly, a local focus on growth is likely to result in local growth, and we interpreted that to mean increasing property prices would exclude disadvantaged people from the housing market. By contrast, a reading of global SSP4 at the local scale suggests that rural areas would suffer the brunt of inequality as wealth concentrates in urban areas, so a small rural township like Forrest would have a substantial disadvantaged population. The other divergent pathway, the low or de-growth scenario found in LSP 3 (people and planet), does not exist in the global SSPs. The idea of creating a low or de-growth pathway was mentioned in multiple sessions during the most recent meeting on the SSPs, so there is demand for such a narrative within the framework (O'Neill et al. 2019). Recent urgent calls from the scientific community to halt climate change have also advocated a low or de-growth agenda (Ripple et al. 2019), so adding such pathways to the suite of global SSPs should be strongly considered. Their inclusion within the LSPs is more than warranted, as D'Alessandro et al. (2020) undertook modelling of green and de-growth pathways and concluded that strong social policies need to be introduced alongside green economic policies to avoid negative social outcomes, strengthening the argument for holistic SDG implementation.

\section{Innovation and contribution}

One reason the SSPs and SDGs have not previously been linked in the manner in which we have done here is likely because the SSPs were designed for climate change research. By developing the sustainability pathway space, we have extended the SSPs into the realm of sustainability research without disrupting the fundamental basis of its original usecase. This new conceptual space allows for any sustainability pathways to be developed with the framework used to create the SSPs, not just pathways focused on the SDGs.

Our method of co-developing pathways through contextual analysis and community engagement is not fundamentally new (for example Palazzo et al. 2017; Nilsson et al. 2017) but using these processes to localize the SDGs and the SSPs to create pathways is a new contribution. Additionally, the process of localization wherein priority SDGs are chosen by the community has not been reported before. One of the techniques used here for community engagement (the Listening Post) has not previously been described in the literature; in addition, these techniques can be used for any co-creative community engagement processes.

\section{Limitations}

One consideration of adapting the SSPs for use with the SDGs is that the SDGs have a horizon of 2030, while the SSPs describe pathways along which trends develop over time (O'Neill et al. 2017). This does not preclude conceptualizing our pathways as extending beyond 2030; there is also much discussion in the literature about whether the SDGs can be achieved by 2030 (Gao and Bryan 2017; Zimm, Sperling and Busch 2018; 2018; Allen et al. 2019; Bryan, Hadjikakou and Moallemi 2019). For instance, considering LSP 
3 (people and planet) in particular: reforming the social and financial systems will require a longer time frame than the next ten years, so the reform agenda put forward by the degrowth scenario is unlikely to be totally fulfilled. But at the same time, such policy change implemented at a localized scale could act as a microcosm experiment for de-growth and could lay the groundwork for broader social and economic de-growth reform. So, while the local socioeconomic pathways represent different levels of fulfillment of the SDGs, it is not essential that they describe a future which must be reached by 2030; rather that they describe pathways beyond 2030 in the context of SDG implementation.

We found that in Forrest, there was a clear consensus on which SDGs were most relevant for the community, but this will not always be the case for different communities. This is unquestionably one of the difficulties in community based participatory research; but working with trained facilitators is one way to increase the chances a collective community vision can be elicited. Fundamentally, for a successful community-driven implementation of the SDGs, participatory processes are essential (Voinov et al. 2016).

\section{Conclusion}

Sustainability research and the SDGs are a field in need of a standardized method for developing pathways to explore possible futures. Such methods already exist in the SSPs, and the framework on which they are based is flexible enough to adapt to a broader sustainability agenda. By linking the existing pathway framework of the SSPs to the sustainability agenda of the SDGs, we have provided a consistent, tested method for creating sustainability pathways which are aligned with global initiatives, and thus can be applied to any SDG implementation. We also developed a sustainability pathway space based upon the three dimensions of the SDGs (people, prosperity and planet) that can inform future research for extending the SSPs from climate scenarios to sustainability science.

Working with local communities to localize and implement the SDGs realizes a foundational component of the UN 2030 Agenda for Sustainable Development. We engaged with communities to localize the SDGs and generated visions using a range of engagement techniques, and co-created local socioeconomic pathways with them. This empowered the community to take ownership of their own sustainability ambitions and advocate for their achievement with funding bodies and decision-makers. The bottom-up, grassroots nature of our engagement and co-development work with the community ensures a deeply felt connection with the SDGs by the community and a much greater chance of success in achieving their desired sustainability outcomes.
Electronic supplementary material The online version of this article (https://doi.org/10.1007/s11625-021-00921-2) contains supplementary material, which is available to authorized users.

Acknowledgements We acknowledge the contributions of our community engagement collaborators: George O'Dwyer and David Rourke from the Department of Environment, Land, Water and Planning of Victoria (Australia); the Forrest General Store, and the members of the Forrest Gateway Project Steering Committee from the Forrest community; and Dianty Ningrum from Monash University.

Author's contribution All authors contributed to the study's conception and design. Material preparation, data collection and analysis were performed by KS, EAM, EA, MB and BS. Funding acquisition and supervision were coordinated by $\mathrm{BAB}$. The first draft of the manuscript was written by KS and all authors commented on previous versions of the manuscript. All authors read and approved the final manuscript.

Funding This work is funded by The Ian Potter Foundation and Deakin University through the Local SDGs Program (www.localSDGs.org).

Data availability Data for this research are not publicly available. The data that were generated are qualitative, and primarily consist of statements and feedback from community members. Releasing this data would violate our human ethics research approval: "Digital copies of the data will be stored onto hard drive, password protected and only accessible by the Project Team researchers. Data will be stored 5 years after publications and destroyed through deletion of computer files".

\section{Compliance with ethical standards}

Conflict of interest The authors have no conflicts of interest to declare that are relevant to the content of this article.

Ethical approval This research has obtained its ethics approval through Deakin University (reference number 2019-249). Informed consent was obtained from all participants.

\section{References}

Absar SM, Preston BL (2015) Extending the shared socioeconomic pathways for sub-national impacts, adaptation, and vulnerability studies. Global Environ Chang 33:83-96

Allen C, Metternicht G, Wiedmann T (2016) National pathways to the Sustainable Development Goals (SDGs): a comparative review of scenario modelling tools. Environ Sci Policy 66:199-207

Allen C, Metternicht G, Wiedmann T (2017) An iterative framework for National Scenario Modelling for the Sustainable Development Goals (SDGs). Sustain Dev 25(5):372-385

Allen C, Metternicht G, Wiedmann T, Allen (2018) Initial progress in implementing the Sustainable Development Goals (SDGs): a review of evidence from countries. Sustain Sci 13(5):1453-1467

Allen C, Metternicht G, Wiedmann T, Pedercini M, Allen (2019) Greater gains for Australia by tackling all SDGs but the last steps will be the most challenging. Nat Sustain 2(11):1041-1050

Australian Bureau of Statistics 2017, '2016 Census QuickStats: Forrest (Vic.)', Australian Bureau of Statistics, retrieved Apr 15, 2020, from https://quickstats.censusdata.abs.gov.au/census_services/ getproduct/census/2016/quickstat/SSC20933. 
Baptiste N (1995) Professional development always growing and learning: the ORID — a technique to enhance communication. Day Care Early Edu 22(4):39-40

Basco-Carrera L, Warren A, van Beek E, Jonoski A, Giardino A (2017) 'Collaborative modelling or participatory modelling? A framework for water resources management.' Environ Model Softw 91:95-110

Bennett NJ, Kadfak A, Dearden P (2016) Community-based scenario planning: a process for vulnerability analysis and adaptation planning to social-ecological change in coastal communities. Environ Dev Sustain 18(6):1771-1799

Berland A (2019) Lessons from the field for community engagement and accountability. Int J Health Gov 24(4):261-266

Breuer A, Janetschek H, Malerba D (2019) Translating Sustainable Development Goal (SDG) interdependencies into policy advice. Sustainability 11(7):2092

Bryan BA, Hadjikakou M, Moallemi EA (2019) Rapid SDG progress possible. Nat Sustain 2(11):999-1000

Byers E, Gidden M, Leclère D, Balkovic J, Burek P, Ebi K, Greve P, Grey D, Havlik P, Hillers A, Johnson N, Kahil T, Krey V, Langan S, Nakicenovic N, Novak R, Obersteiner M, Pachauri S, Palazzo A, Parkinson S, Rao ND, Rogelj J, Satoh Y, Wada Y, Willaarts B, Riahi K (2018) Global exposure and vulnerability to multisector development and climate change hotspots. Environ Res Lett 13(5):055012

Coenen F (2009) Local agenda 21: "meaningful and effective" participation? In: Coenen FHJM (ed) Public participation and better environmental decisions: the promise and limits of participatory processes for the quality of environmentally related decisionmaking. Springer, Dordrecht, pp 165-182

Crespo Cuaresma J, Fengler W, Kharas H, Bekhtiar K, Brottrager M, Hofer M (2018) Will the sustainable development goals be fulfilled? Assessing present and future global poverty. Palgrave Commun 4(1):29

D’Alessandro S, Cieplinski A, Distefano T, Dittmer K (2020) Feasible alternatives to green growth. Nat Sustain 3(4):329-335

DELWP 2014 Effective engagement: building relationships with community and other stakeholders. The engagement toolkit, The State of Victoria Department of Environment and Primary Industries, Melbourne

Ebi KL, Hallegatte S, Kram T, Arnell NW, Carter TR, Edmonds J, Kriegler E, Mathur R, O’Neill BC, Riahi K, Winkler H, Van Vuuren DP, Zwickel T (2014) A new scenario framework for climate change research: background, process, and future directions. Clim Chang 122(3):363-372

ElMassah S, Mohieldin M (2020) Digital transformation and localizing the Sustainable Development Goals (SDGs). Ecol Econ 169:106490

Folke C, Biggs R, Norström AV, Reyers B, Rockström J 2016 'Socialecological resilience and biosphere-based sustainability science', Ecology and Society, vol. 21, no. 3, retrieved from https://www. ecologyandsociety.org/vol21/iss3/art41/.

Frame B, Lawrence J, Ausseil A-G, Reisinger A, Daigneault A (2018) Adapting global shared socio-economic pathways for national and local scenarios. Clim Risk Manage 21:39-51

Fuldauer LI, Ives MC, Adshead D, Thacker S, Hall JW (2019) Participatory planning of the future of waste management in small island developing states to deliver on the Sustainable Development Goals. J Clean Prod 223:147-162

Gao L, Bryan BA (2017) Finding pathways to national-scale landsector sustainability. Nature 544(7649): 217

Gil JDB, Daioglou V, van Ittersum M, Reidsma P, Doelman JC, van Middelaar CE, van Vuuren DP (2019) Reconciling global sustainability targets and local action for food production and climate change mitigation. Global Environ Chang 59:101983
Gössling S, Scott D, Hall CM (2020) Pandemics, tourism and global change: a rapid assessment of COVID-19. J Sustain Tour 29(1):1-20

Halbe J, Holtz G, Ruutu S (2020) Participatory modeling for transition governance: linking methods to process phases. Environ Innov Soc Trans 35:60-76

van Hees S, Horstman K, Jansen M, Ruwaard D (2020) How does an ageing policy translate into professional practices? An analysis of kitchen table conversations in the Netherlands. Euro J Social Work 23(2):215-226

Hinz R, Sulser TB, Huefner R, Mason-D’Croz D, Dunston S, Nautiyal S, Ringler C, Schuengel J, Tikhile P, Wimmer F, Schaldach R (2020) Agricultural development and land use change in India a scenario analysis of trade-offs between UN Sustainable Development Goals (SDGs). Earth's Future 8(2):e2019EF1287

Holkup PA, Tripp-Reimer T, Salois EM, Weinert C (2004) Community-based participatory research: an approach to intervention research with a native American Community. Advances in Nursing Science, vol. 27, no. 3, retrieved from <https://journals.lww. com/advancesinnursingscience/Fulltext/2004/07000/Community_ based_Participatory_Research_An.2.aspx $>$.

Jonas M, Ometto JP, Batistella M, Franklin O, Hall M, Lapola DM, Moran EF, Tramberend S, Queiroz BL, Schaffartzik A, Shvidenko A, Nilsson SB, Nobre CA (2014) Sustaining ecosystem services: overcoming the dilemma posed by local actions and planetary boundaries. Earth Future 2(8):407-420

Jones P, Comfort D (2020) A commentary on the localisation of the sustainable development goals. J Public Affairs 20(1):e1943

Kanter DR, Schwoob MH, Baethgen WE, Bervejillo JE, Carriquiry M, Dobermann A, Ferraro B, Lanfranco B, Mondelli M, Penengo C, Saldias R, Silva ME, de Lima JMS (2016) Translating the sustainable development goals into action: a participatory backcasting approach for developing national agricultural transformation pathways. Global Food Security-Agriculture Policy Econ Environ 10:71-79

Kok K, Pedde S, Gramberger M, Harrison PA, Holman IP (2019) New European socio-economic scenarios for climate change research: operationalising concepts to extend the shared socio-economic pathways. Reg Environ Chang 19(3):643-654

Kriegler E, O’Neill BC, Hallegatte S, Kram T, Lempert RJ, Moss RH, Wilbanks T (2012) The need for and use of socio-economic scenarios for climate change analysis: a new approach based on shared socio-economic pathways. Global Environ Chang 22(4):807-822

Kroll C, Warchold A, Pradhan P (2019) Sustainable Development Goals (SDGs): are we successful in turning trade-offs into synergies? Palgrave Commun 5(1):140

Longhurst R (2016) Semi-structured interviews and focus groups. In: N Clifford, M Cope, T Gillespie S French (eds) Key methods in geography, SAGE Publications, pp. 143-156, retrieved from $<$ https://books.google.com.au/books?id=7hcFDAAAQBAJ>.

Lucas PL, Hilderink HBM, Janssen PHM, S KC, van Vuuren DP, Niessen L (2019) Future impacts of environmental factors on achieving the SDG target on child mortality - a synergistic assessment. Global Environ Chang 57:101925

Moallemi EA, Malekpour S, Hadjikakou M, Raven R, Szetey K, Moghadam MM, Bandari R, Lester R, Bryan BA, Moallemi (2019) Local Agenda 2030 for sustainable development. Lancet Planet Health 3(6):e240-e241

Moallemi EA, Eker S, Gao L, Hadjikakou M, Kwakkel J, Reed PM, Obersteiner M, Bryan BA (2020a) Global pathways to sustainable development to 2030 and beyond. arXiv:2012.04333 [econ.GN]

Moallemi EA, Malekpour S, Hadjikakou M, Raven R, Szetey K, Ningrum D, Dhiaylhaq A, Bryan BA (2020b) Achieving the sustainable development goals requires transdisciplinary innovation at the local scale. One Earth 3(3):300-313 
Moyer JD, Hedden S (2020) Are we on the right path to achieve the sustainable development goals? World Dev 127:104749

Nam T (2013) Citizen participation in visioning a progressive city: a case study of Albany 2030. Int Rev Public Admin 18(3):139-161

Nilsson AE, Bay-Larsen I, Carlsen H, van Oort B, Bjørkan M, Jylhä K, Klyuchnikova E, Masloboev V, van der Watt L-M (2017) Towards extended shared socioeconomic pathways: a combined participatory bottom-up and top-down methodology with results from the Barents region. Global Environ Chang 45:124-132

O’Neill BC, Conde C, Ebi K, Friedlingstein P, Fuglestvedt J, Hasegawa T, Kok K, Kriegler E, Monteith S, Pichs-Madruga R, Preston BL, Sillman J, van Ruijven B, Van Vuuren D (2019) Forum on scenarios of climate and societal futures: meeting report. Pardee Center Working Paper, University of Denver, Denver, CO.

O’Neill BC, Kriegel E, Ebi K, Kemp-Benedic E, Riahi K, Rothman DS, van Ruijven B, Van Vuuren D, Birkmann J, Kok K, Levy M, Solecki W 2017. The roads ahead: Narratives for shared socioeconomic pathways describing world futures in the 21 st century. Global Environmental Change, p. 169.

O’Neill BC, Kriegler E, Riahi K, Ebi KL, Hallegatte S, Carter TR, Mathur R, Vuuren DP (2014) A new scenario framework for climate change research: the concept of shared socioeconomic pathways. Clim Chang 3:387

Palazzo A, Vervoort JM, Mason-D’Croz D, Rutting L, Havlík P, Islam S, Bayala J, Valin H, Kadi Kadi HA, Thornton P, Zougmore R (2017) Linking regional stakeholder scenarios and shared socioeconomic pathways: quantified West African food and climate futures in a global context. Global Environ Chang 45:227-242

Patole M (2018) Localization of SDGs through disaggregation of KPIs. Economies 6(1):17

Purvis B, Mao Y, Robinson D (2019) Three pillars of sustainability: in search of conceptual origins. Sustain Sci 14(3):681-695

QSR International Pty Ltd 2018, NVivo qualitative data analysis software.

Reimann L, Merkens J-L, Vafeidis AT (2018) Regionalized shared socioeconomic pathways: narratives and spatial population projections for the Mediterranean coastal zone. Reg Environ Chang 18(1):235-245

Riahi K, van Vuuren DP, Kriegler E, Edmonds J, O’Neill BC, Fujimori S, Bauer N, Calvin K, Dellink R, Fricko O, Lutz W, Popp A, Cuaresma JC, Kc S, Leimbach M, Jiang L, Kram T, Rao S, Emmerling J, Ebi K, Hasegawa T, Havlik P, HumpenAaAaAeA der F, Da Silva LA, Smith S, Stehfest E, Bosetti V, Eom J, Gernaat D, Masui T, Rogelj J, Strefler J, Drouet L, Krey V, Luderer G, Harmsen M, Takahashi K, Baumstark L, Doelman JC, Kainuma M, Klimont Z, Marangoni G, Lotze-Campen H, Obersteiner M, Tabeau A, Tavoni M (2017) The Shared Socioeconomic Pathways and their energy, land use, and greenhouse gas emissions implications: an overview. Global Environmental Change.

Ripple WJ, Wolf C, Newsome TM, Barnard P, Moomaw WR (2019) World scientists warning of a climate emergency, BioScience, no. biz088, retrieved Nov 18, 2019, from https://doi.org/10.1093/ biosci/biz088>.

van Ruijven B, Levy MA, Agrawal A, Biermann F, Birkmann J, Carter TR, Ebi KL, Garschagen M, Jones B, Jones R, Kemp-Benedict E, Kok M, Kok K, Lemos MC, Lucas PL, Orlove B, Pachauri S, Parris TM, Patwardhan A, Petersen A, Preston BL, Ribot J, Rothman DS, Schweizer VJ (2014) Enhancing the relevance of shared socioeconomic pathways for climate change impacts, adaptation and vulnerability research. Clim Chang 3:481

Seyfang G, Smith A (2007) Grassroots innovations for sustainable development: Towards a new research and policy agenda. Environ Polit 16(4):584-603
SGS Economics and Planning (2018) 2018 GDP report: gap in economic growth between cities and regions starting to close, retrieved Jun 19, 2019, from <https://www.sgsep.com.au/assets/ main/Publications/SGS-Economics-and-Planning_EconomicPerformance-of-Australian-Cities-and-Regions-UPDATED-2020. pdf>.

Shalowitz MU, Isacco A, Barquin N, Clark-Kauffman E, Delger P, Nelson D, Quinn A, Wagenaar KA (2009) Community-based participatory research: a review of the literature with strategies for community engagement. Journal of Developmental and Behavioral Pediatrics, vol. 30, no. 4, retrieved from <https://journals.lww. com/jrnldbp/Fulltext/2009/08000/Community_Based_Participat ory_Research_A_Review.13.asp $x>$.

Sterling EJ, Pascua P, Sigouin A, Gazit N, Mandle L, Betley E, Aini J, Albert S, Caillon S, Caselle JE, Cheng SH, Claudet J, Dacks R, Darling ES, Filardi C, Jupiter SD, Mawyer A, Mejia M, Morishige K, Nainoca W, Parks J, Tanguay J, Ticktin T, Vave R, Wase V, Wongbusarakum S, McCarter J (2020) Creating a space for place and multidimensional well-being: lessons learned from localizing the SDGs. Sustain Sci 15(4):1129-1147

Stewart K (1994) Speaking out for a suburban town centre: The Salisbury experience. In: W Sarkissian, K Walsh (eds). Community Participation in Practice: Casebook. Institute for Sustainability and Technology Policy, Murdoch University, Perth, pp. 163-178.

Tan DT, Siri JG, Gong Y, Ong B, Lim SC, MacGillivray BH, Marsden $\mathrm{T}$ (2019) Systems approaches for localising the SDGs: co-production of place-based case studies. Glob Health 15(1):85

UN 2015, 'Transforming our world: the 2030 Agenda for Sustainable Development', retrieved July 22, 2019, from <https://sustainabl edevelopment.un.org/post2015/transformingourworld $>$.

UN 2017, 'Localizing the SDGs' retrieved Sep 4, 2019, from <https:// www.localizingthesdgs.org/>.

UN 2020, Shared responsibility, global solidarity: responding to the socio-economic impacts of COVID-19, United Nations, retrieved May 18, 2020, from <https://www.un.org/sites/un2.un.org/files/ sg_report_socio-economic_impact_of_covid19.pdf $>$.

Voinov A, Kolagani N, McCall MK, Glynn PD, Kragt ME, Ostermann FO, Pierce SA, Ramu P (2016) Modelling with stakeholders-next generation. Environ Model Softw 77:196-220

van Vuuren DP, Kok MTJ, Girod B, Lucas PL, de Vries B (2012) Scenarios in global environmental assessments: key characteristics and lessons for future use. Global Environ Chang 22(4):884-895

van Vuuren DP, Kriegler E, O’Neill BC, Ebi KL, Riahi K, Carter TR, Edmonds J, Hallegatte S, Kram T, Mathur R, Winkler H (2014) A new scenario framework for climate change research: scenario matrix architecture. Clim Chang 3:373

van Vuuren DP, Stehfest E, Gernaat DEHJ, Doelman JC, van den Berg M, Harmsen M, de Boer HS, Bouwman LF, Daioglou V, Edelenbosch OY, Girod B, Kram T, Lassaletta L, Lucas PL, van Meijl H, Müller C, van Ruijven BJ, van der Sluis S, Tabeau A (2017) Energy, land-use and greenhouse gas emissions trajectories under a green growth paradigm. Global Environ Chang 42:237-250

Walsh B, Ciais P, Janssens IA, Peñuelas J, Riahi K, Rydzak F, van Vuuren DP, Obersteiner M (2017) Pathways for balancing CO2 emissions and sinks. Nat Commun 8(1):14856

Yang S, Cui X (2019) Building regional sustainable development scenarios with the SSP framework. Sustainability 11(20):5712

Zandersen M, Hyytiäinen K, Meier HEM, Tomczak MT, Bauer B, Haapasaari PE, Olesen JE, Gustafsson BG, Refsgaard JC, Fridell E, Pihlainen S, Le Tissier MDA, Kosenius A-K, Van Vuuren DP (2019) Shared socio-economic pathways extended for the Baltic Sea: exploring long-term environmental problems. Reg Environ Chang 19(4):1073-1086 
Zhang X-Y (2015) Some reflections on researches of Future Earth changes in air quality and climate. Adv Future Earth Res 6(2): 126-130

Zimm C, Sperling F, Busch S (2018) Identifying sustainability and knowledge gaps in socio-economic pathways Vis-à-Vis the Sustainable Development Goals. Economies 6(2):20
Publisher's Note Springer Nature remains neutral with regard to jurisdictional claims in published maps and institutional affiliations. 